\title{
Moral Rights in the Information Society
}

\author{
Ying Zhou \\ Zhonghao Law Firm (Shanghai) Office, Shanghai, China \\ Email: zhouyingnice@126.com
}

Received 14 April 2014; revised 12 May 2014; accepted 6 June 2014

Copyright (C) 2014 by author and Scientific Research Publishing Inc.

This work is licensed under the Creative Commons Attribution International License (CC BY).

http://creativecommons.org/licenses/by/4.0/

(c) (i) Open Access

\section{Abstract}

This essay mainly concentrates on the value of moral rights in this ever-developing society. Above all, the background of moral rights is provided, giving us a brief introduction. There are two categories of rights in copyright system; one is economic rights, which can bring economic interests to right holders directly; the other one is moral rights, which stands for the creator's personality but can't produce economic interests directly. As to international regulation, Art.6 bis of the Berne Convention has some clauses on such rights. In moral rights system, rights are divided into four kinds: the right to be identified as an author or a director-the paternity right or the right to be identified; the right to object to derogatory treatment of work-the integrity right; the false attribution of work-the false attribution right; and the right to privacy of certain photographs and films - the privacy right. All these rights are beneficial as they can protect creators' rights from the four aspects. Form this standpoint, it is reasonable to grant moral rights. However, in the following, some shortcomings of moral rights are to be displayed as these rights are unable to meet the requirements of the modern society. With the advent and development of internet, collectivization, digitization and employment, some measures should be taken so as to adjust the moral rights system to keep pace of the society. From my standpoint, it is still justified to keep moral rights existing but we should make some adaptations of them in order to meet the needs of this digital era and the information society.

\section{Keywords}

Moral Rights, Justified, Conflicting Interests

\section{Introduction}

With the rapid development of technology and science, a large number of people begin to consider whether moral rights are still justified and reasonable in the information age and digital era, as such rights always become an obstacle of the society. Moral rights in contemporary society, different from the romantic idea in the 
eighteenth century "claiming for the creative artist a unique sensibility and foresight", are hampering the social development in various ways.

As a matter of fact, there are two opinions of the puzzling issues. Some argue that we should discard such rights as they are preventing our society form making greater progress. However, the opposite side holds that as long as we take some measures such as moral rights to reform or reach an agreement concerning moral rights, the adverse effect of moral rights will disappear.

This essay will display the conflicting interests in the ever-developing society due to moral rights. Also, some analysis will be provided to make a judgment of the confusing issues: it is necessary to keep moral rights existing, and is it worthwhile to make some adaptation of copyright system. Furthermore, some advices will be given to set up a much better moral rights system, as well as to harmonize the conflicting interests.

\section{Background of Moral Rights}

Copyright, an IPR granted by national law, which shall provide protection for authors, directors, performers and so on by preventing others form exploiting commercially or in some other relevant ways, has always been divided into two categories: economic rights and moral rights. The former, depending on the type of protected work, gives rights to produce, reproduce, present, communicate, publish, or authorize works so it can bring interests to the right holders directly. However, the latter, protects the personal relation of the author to its work, as Hegel's property/personality theory saying "author is the spiritual father of the work", which Germany law focuses on (Cornish \& Llewelyn, 2003). In common law countries, such as France, according to the description of "droit moral" in Art.6 of the French Copyright Law, the definition of moral rights is:

"The author shall enjoy the right to respect for his name, his authorship and his work. This right shall be attached to his person. It shall be perpetual, inalienable and imprescriptible" (French Copyright Law, Art.6).

In terms of international regulation, concluding form Art.6 bis of the Berne Convention:

“(1) Independently of the author's economic rights, and even after the transfer of the said rights, the author shall have the right to claim authorship of the work and to object to any distortion, mutilation or other modification of, or other derogatory action in relation to, the said work, which would be prejudicial to his honor or reputation. (2) The rights granted to the author in accordance with the preceding paragraph shall, after his death, be maintained, at least until the expiry of the economic rights, and shall be exercisable by the persons or institutions authorized by the legislation of the country where protection is claimed. However, those countries whose legislation, at the moment of their ratification of or accession to this Act, does not provide for the protection after the death of the author of all the rights set out in the preceding paragraph may provide that some of these rights may, after his death, cease to be maintained. (3) The means of redress for safeguarding the rights granted by this Article shall be governed by the legislation of the country where protection is claimed" (The Berne Convention, Art.6 bis, 1886).

There are independent rights deriving form moral rights, including rights to claim authorship, to object to certain modifications and other derogatory actions which will be prejudicial to an author's honor or reputation.

\section{Four Rights in Moral Rights System}

The 1988 Act, which introduces moral rights provisions into UK law, defines four distinct moral rights:

“(a) the right to be identified as an author or a director - the paternity right or the right to be identified; (b) the right to object to derogatory treatment of work - the integrity right; (c) the false attribution of workthe false attribution right; and; (d) the right to privacy of certain photographs and films - the privacy right" (1988 Act, Chapter 4, Section 77-89).

Consequently, with regard to these four aspects, the protection of moral rights has brought lots of benefits for right holders.

In the first place, the right to be identified, also called the paternity right, is given to the creators of literary, dramatic, musical and artistic works, and also the directors of films. The reason for this right is that the name of the author performs a number of different roles: it facilitates the management of intellectual works (through in- 
dexes, catalogues, and bibliographies), the channeling of royalties (for example form the Public Lending Right), the interpretation of the work (insofar as it provides a psychological or biographical history of the author), the celebration, reward, and sustenance of authorial talent or genius, and the construction of the individual as the creator of an intellectual oeuvre (Bently \& Sherman, 2008). As a result, the right is, not only against the failure of naming the creator, but also the plagiarism of the work. The authors or directors, have a belief that the creation stands for their personality, as they have devoted a great deal of effort to the work. Consequently, it is worthy showing creator's name in an appropriate place on all copies of the work and claiming authorship of it at all times, especially when there is someone else Plagiarism it.

In the second place, the moral right of integrity, which lasts for the same time as the copyright in the relevant work, is the right to object to derogatory treatment of a work, or any part of it. Treatment can be interpreted as an addition, deletion, adaptation, translation of the work or any other forms which can change the key point of the creation. As long as the treatment constitutes distortion of the work, or is prejudicial to the honor or reputation of the author or director, it becomes a derogatory treatment. Creators feel some degree of responsibility for the work and are desirable to protect their reputation. When literary, dramatic, musical works, film, sound recording or artistic works is published commercially, performed in public, communicated to the public without creators' permission or license, or in any other form of derogatory treatment, it constitutes an infringement.

In the third place, the false attribution right is described as the converse of the paternity right. If a person issues copies of a work to public, or exhibits in public an artistic work where there is a false attribution and he/she knows the attribution is false, he/she infringes the creators' attribution right. So the false attribution right protects author's or director's paternity right by this means. Thus, for example, the artistic executors of Picasso or Moore will be able to use this right to prevent anyone trading in works purportedly, but not in fact, made by them, as against using copyright law to prevent the unauthorized reproduction of works truly made by them.

In the fourth place, under the rules of the 1988 Act, where a person commissions a photograph or a film for private or domestic purposes, and that work attracts copyright, he/she has the right to object to issuing copies to the public, public exhibition or showing, broadcasting or cable-casting. Any person who does, or authorises the doing of, any of these acts without the permission of the person who commissioned the photograph, infringes the right (Cornish \& Llewelyn, 2003). From this, we can conclude that the privacy right is to restrict copy-right owners to deal freely with the photograph in order to protect the privacy of the person in the photograph. In consideration that it will be inconvenient if permission of all in a group is required, so the commissioner is put on behalf.

From the above, we are able to see that moral rights have provided strong protection for right holders as there are four categories of rights, particularly the rights to be named and to object to derogatory treatment. The protection is beneficial to authors or directors, prohibiting others to do any infringement which can be prejudicial to their honor or reputation. Meanwhile, creators will be much more passionate and willing to create more works as moral rights are playing an important role in protecting their creation.

\section{The Impact Which Moral Rights Have Brought to Contemporary Society}

It is known to all that moral rights work as the extension of the personality of its author and the strong protection is "a safeguard of the cultural heritage" (Nocella, 2008). Nevertheless, nowadays, with the development of technology and science, moral rights protection becomes "the target of cultural and high tech firms, which are users and creators of works" (Nocella, 2008). As a consequence, moral rights protection becomes controversial, not only in the area of culture, but also in the economy area. The real problem is that how to balance the interests between the authors and that of others. From the following aspects, I will display how moral rights conflict with this new world.

\subsection{The Internet}

The first item that contradicts with moral rights is the Internet. The Internet, a global network of networks, with a large quantity of the world's population having access to it, connects university, government, commercial and other computers in other countries. As there is no charge of the net, the internet is an inherently participative medium. With the internet, everybody is able to publish information, provide new services, send electronic mails, chat with friends and relatives online all around the world, and obtain information on a wide variety of subjects. 
"To recap, the internet technologies can be described as follows: (a) WWW-WWW was originally conceived as a means of displaying documents in so-called hypertext format. However, it has progressively expanded to allow for display of other visual information such as picture graphics and computer video clips as well as the replay of sounds: many web pages now disclose a kaleidoscopic array of pictures, colors, movement and sound and web sites are frequently assessed on the bases not only of technical prowess, but of artistic quality. (b) E-mail—a system for sending messages electronically to other users, the internet version of e-mail also allows attachments, computer files tagged to the message which can contain data, pictures, sounds, programs or any other digitized material. (c) Newsgroups-A system which allows the user access to the electronic equivalent of a bulletin board from which she/he can read messages pertaining to the particular topic of interest of the group(e.g. news.btinternet.com) and to which she/he can write in response” (Lea, 1999).

Firstly, in relation to the world wide web (WWW), as Gary Lea said, at the very beginning of HTML (hypertext mark-up language) computer program, it may constitute an infringement when we copy underlying page codes to cut down on WWW site. Nonetheless, to which extent it may be an infringement of moral rights depends on different countries: as in the United Kingdom, it exempts computer programs form moral rights protection in its copyright legislation, even in France, a country with moral rights system, has limitations on the assertions of moral rights so as to allow certain transformation to computer programs when it is essential. Actually, it has become a widespread practice already as people have to use or debug in our daily life. Can you imagine how will we go on with our work and study if there are plenty of restrictive regulations, due to strong moral rights protection, when we make some alternations to computer programs?

Secondly, one prominent feature of the Internet is the linking process, through which users can move between pages by a single click on a link provided on a web page. This process includes surface linking and deep linking. The former links to the homepage of another website, whilst the latter enables users to surf deeply within another website. Both of these two links could lead to a derogatory conduct with regard to a work exists. Thus, anyone who inserts a link should be liable because he/she has republished the material on the linked website.

Thirdly, as we all know, e-mail and newsgroup are playing an important role in these days. E-mail is a system convenient for computer users to exchange messages and communicate with each other. One advantage of it is that you can send messages to anyone else as long as you have got his/her e-mail and your recipients could respond at their convenience. In addition to e-mail, newsgroup, another communication tool, is one of the primary ways people who have common or similar interests would like to use to interact with one another. Nevertheless, the operation of e-mail and newsgroups are generating some moral rights issues. On the one hand, the action of snipping part of a message becomes controversial. Some argue that the snipping represents an infringement to the rights of integrity, paternity or both of them. On the other hand, as Gary Lea suggests, some Internet users are willing to delete or filter part of their messages or mails if there are some objectionable and offensive words and phrases. As a matter of fact, it is a violation to the sender's integrity right. This issue is really confusing, because there may be two difficulties when stopping it: “(a) stifling the recipient's rights in relation to privacy and freedom of belief and (b) preventing a practice that happens in a significant number of private dwellings, an area largely beyond the effective grip of copyright controls” (Lea, 1999). As a consequence, the strong protection has fallen foul of the information society today, causing much confusion and puzzlement.

\subsection{Collectivisation}

As we have witnessed the rapid development of modern society, it is reasonable that persons get to work together in a group and cooperate with one another so as to produce a work. This is the so-called collectivization. Maybe it is a difficult matter for some people to adopt this notion, and they stick to the romantic notion that the author is a single creative force behind a work. Nevertheless, could you think about this: how can a person finish a television broadcast alone?

With the advent of modern artistic and cultural activity, it has become gradually difficult to authorize a single creator to produce a work. Here come some moral rights issues: for the authors' rights system, it is a little hard to make some adjustment and design a suitable legal framework with the purpose of meeting the protection requirements of multi-authored works and creative interests. Gary Lea has taken CD-ROMs, WWW pages and electronic library services for examples. A large number of tough problems occur: how to identify right holders properly and secure suitable agreements over use if the work is derived form pre-existing works, who is the au- 
thor of the content added to the CD-ROM, is there any relevant legislation appropriate to apply to and so forth. All these have become much more acute with the advent of digital age and information society.

\subsection{Digitisation}

Turning to digitization, it is a process which can convert information into binary data (a digital format, which can be processed by computers and many other devices with computing capacity, like digital cameras, digital hearing aids and so on) so that the material can be identified. It allows unlimited copying, adaptation, or transformation of material, no matter in a creative or destructive way. The destructive ways includes: "pirates copying recordings of unreleased songs to WWW sites in violation of the right to decide on publication, digitally altering works of art to create an amusing web site graphic in violation of the right of integrity, and so forth" (Lea, 1999). Furthermore, providing with binary data, digitization has a blurring effect which can cause a proliferation of the multi-faceted works. However, the present legislation is desperate, because they have to endeavor to reduce the marginalization in this area.

\subsection{Employment Relationship}

In Black's law dictionary, "employment” is defined as a contract between the employer and employee. Under this contract, the employee provides services, as express or implied, oral or written, whilst the employer controls or directs in details in purpose of a well-structured work. In addition, the employer, who has made a big investment for the creation of a work, owns economic rights undoubtedly. Therefore, it is supposed by them that they are qualified to enjoy full freedom of action in relation to the creation, including any form of modification, adaptation, translation and so forth, so as to produce more economic interests. Conversely, as we all know, "the first and only possible 'owner' of moral rights is the author" (Afori, 2008), so it is unreasonable to make any change of the creation without the author's permission or license, because it is a violation to the author's moral rights, as "the whole essence of moral rights is that they are intended to protect the personal bond between the author and his work, even if he/she is not the owner of the copyright, either because he/she transferred it or because he/she never owned it to begin with" (Afori, 2008). As explained above, it is obvious that there is an inherent conflict between the two parties: the investor-employer who wishes to exploit the work regardless of the employee's moral rights, and the author-employee, who, to the extent, actually has moral rights in the work. So several items should be taken into account when in an employment relationship: How will it affect the employer's economic exploitation of the work when the desired modification is prohibited by the enforcement of the author's moral rights? What about the third parties' economic interests? What kind of modification is regarded as an infringement of the author's moral rights? To what extent should it be prejudicial to an author's honor or reputation? All these tough problems hamper the development of society as employment relationship has become a tendency and is unavoidable in today's world.

Gary Lea, a lecturer and research fellow at the Queen Mary \& Westfield Intellectual Property Research Institute, who is interested in IP, IT and telecommunication law, has given us a few suggested ideas in some relevant areas, focusing on a moral rights reform totally. From his stand, according to the legislation in most civil law countries, it is apparent that moral rights will not vanish immediately. What is more, they will exist for a long time, especially in an increasingly globalised culture. Therefore, there are several suggested solutions about how to balance and reconcile the interests among different parties who intend to pursue their own interests. After all, as a matter of fact, the legal framework of moral rights is falling behind the new world, and it is forcible to make some adaptation of the framework, or to reshape it, so as to keep pace with the information age.

First of all, the Berne Convention is setting up a new system called "Internet-friendly system", providing some basic and necessary requirements. However, it emphasizes that every nation has obligations to develop their own ways to safeguard and protect the rights granted after meeting the preconditions. Obviously, one difficult issue arising during practice is that which rights should be included besides the right of paternity and the right of integrity. But if the protection is subject to both of the specific internal standards and the general external controls, it will make no sense whether the other rights, such as the right to amend, the right to delete or the right to issue, are protected.

Turning next to the question of duration, Gary Lea supports the idea of the monist and common law system that the duration of moral rights should be limited to no longer than the duration of economic rights, with the reason that if there is any potential descendants or institution suitable to manipulate the historical record, and 
even more, whether they are willing to act when the author has died for quite a long time.

Then, consents, waiver or even administration by a third party should be given. Gary Lea argues that the "one stop” negotiation will not weaken moral rights, conversely, their status can be enhanced and the blank of moral rights in commercial processes could be filled gradually.

Meanwhile, on the basis of waiver, consents, administration or licensing, it is of great value to reach a multiagreement or establish a code of good conduct which can be directive for all the participating countries when involving in a specific cultural activity.

Finally, Gary Lea expects not only consent, waiver, administration and existing industry practice, but also the nature of the work in doubt and the aim and purpose of it, should be taken into full consideration, if there is a problem of liability or remedies.

What is more, as to the employment relationship issue, Orit Fischman Afori points out that it is necessary to adopt the new scheme in Israeli mechanism which is in favor of employees' moral rights. He has given us a brief introduction of this scheme by displaying there advantages.

Above all, the scheme is playing an important role in resolving the dilemma. The Israeli mechanism accepts that employees' moral rights are deserved to be respected and nobody is allowed to deprive the rights. However, the courts, should be concentrated on the issue of determining whether such rights are enforceable in every specific case. "Laws confer rights, and courts decide whether their enforcement is compatible with different doctrines, such as good faith and the abuse of rights, as well as the measure of reasonableness" (Afori, 2008). The scheme focuses on the reasonableness of the employer's specific act rather than the entitlement of the employees' moral rights, since it isn't ideal to define the scope of employees' moral rights before the measure is taken as employees are given to a range of degrees of creative freedom. And whether the act is reasonable depends on certain circumstances and it varies case by case.

The second advantage of this scheme is that it refuses to accept the objective standard of measuring the objective defamation to the honor or reputation of the author which only focuses the interests of the author. Conversely, it provides us a well-established and inherently objective standard, holding that it is an absolutely a legal problem- “whether a court can conclude that an act was reasonable under the circumstances or not” (Afori, 2008).

From my perspective, on the one hand, as there are various economic exploitations of creation, the protection of moral rights is undoubtedly essential. Furthermore, we should keep such rights existing for long periods as it safeguards creators' personalities from the following four aspects: the right of paternity, the right of integrity, the false attribution right and the privacy right. On the other hand, to the extent, moral rights limit others' freedom of expression, hamper people to deal with one another, and prevent the development of our society. As a consequence, it is sensible to reach an agreement or set up an industry standard regarding moral rights, so as to balance the economic and moral interests. In addition, as Gary Lea’s point of view, a moral rights reform is worthy in the current copyright world, making some adaptation and adjustment to reach a harmonization.

\section{Conclusion}

This paper examines some moral rights issues that appear in the modern society as a result of digital era and information age.

Frankly speaking, moral rights are beneficial as the protection, to which extent, can promote the creators to produce much more work in the condition that their creation which stands for their personalities is well respected.

Nonetheless, it is clear that moral rights have become an economic and cultural issue as the relevant protection has put an impact on a large number of areas. As we all know, a better balance between the conflicting interests in copyright system is needed, aiming at governing the new interests in contemporary society. With the suggestion provided above, an adjustment of moral rights system should be made to keep the quick pace with the developing society instead of discarding the valuable moral rights.

\section{References}

Afori, O. (2008). Employees’ Moral Rights: The Israeli Solution to an Ongoing Dilemma. European Intellectual Property Review.

Bently, L., \& Sherman, B. (2008). Intellectual Property Law, 244. 
Cornish, W., \& Llewelyn, D. (2003). Intellectual Property: Patents, Copyright, Trade Marks and Allied Rights, $453,465$.

Lea, G. (1999). Perspectives on Intellectual Property. 5, 98-103.

Nocella, L. (2008). Copyright and Moral Rights versus Another’s Right and Droit Moral: Convergence or Divergence? Entertainment Law Review. 
Scientific Research Publishing (SCIRP) is one of the largest Open Access journal publishers. It is currently publishing more than 200 open access, online, peer-reviewed journals covering a wide range of academic disciplines. SCIRP serves the worldwide academic communities and contributes to the progress and application of science with its publication.

Other selected journals from SCIRP are listed as below. Submit your manuscript to us via either submit@scirp.org or Online Submission Portal.
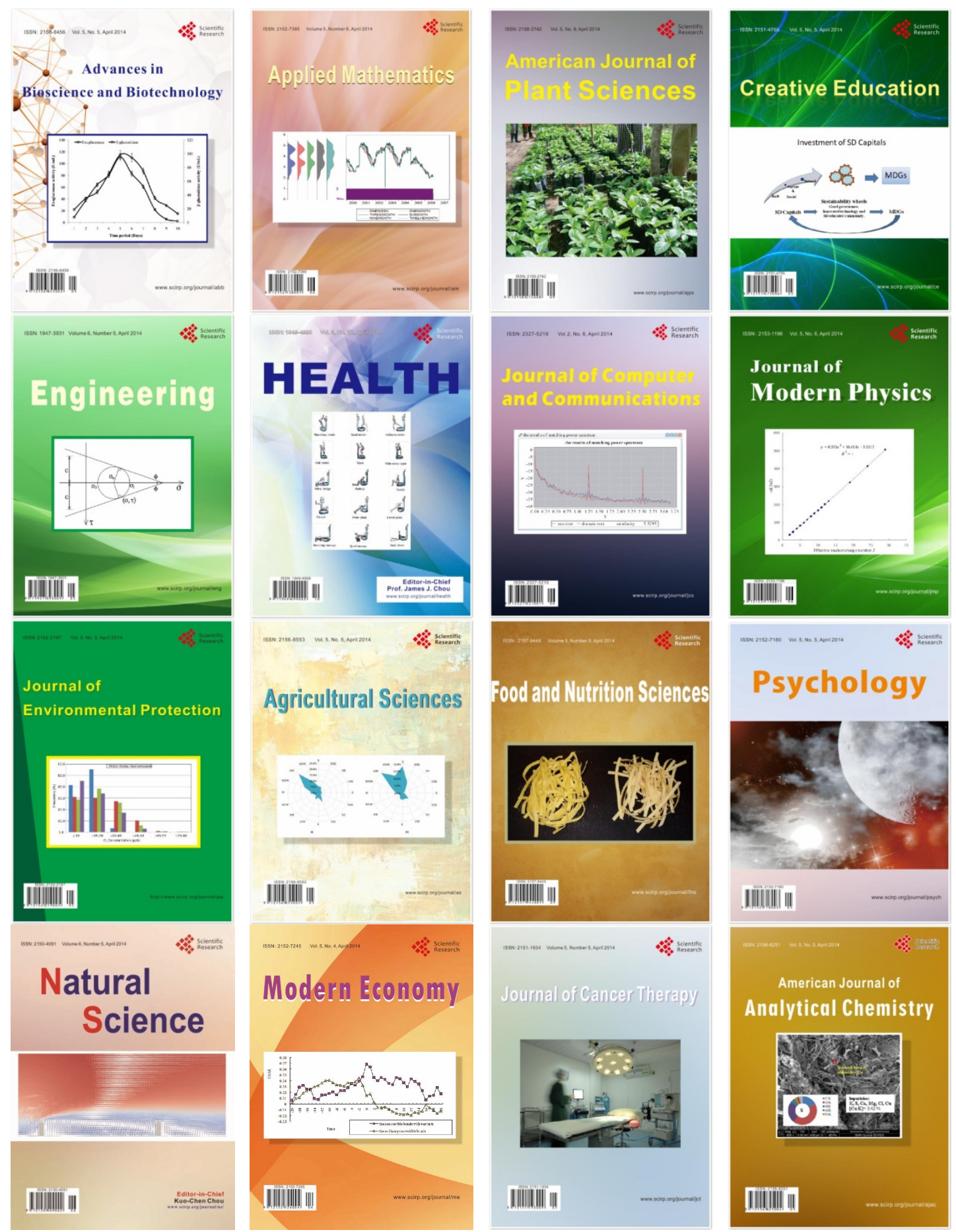